\title{
Normal Cardiogram in the Pulmonary Area
}

\author{
J. N. BERRY AND L. MAGO \\ From the Department of Medicine, Institute of Postgraduate Medical Education and Research, Chandigarh, India
}

The præcordial movements at the apex of the heart have been extensively studied by many workers. Recently, studies of the pulsations in the left lower parasternal area have been published by Gillam, Deliyannis, and Mounsey (1964), Craige and Schmidt (1965), and Benchimol, Wu, and Dimond (1966), though Eddleman and his colleagues (1953) have been recording movements from this area in their kinetocardiographic studies for more than a decade. Agress and Nakakura (1964) find this the most rewarding area for their vibrocardiograms. However, there are few published reports on præcordial movements in the pulmonary area except that by Luisada and Magri (1959), who have mentioned it under the regional variations of the apex cardiogram. Probably, the use of the word apex cardiogram to describe the præcordial movements has had something to do with this restriction to the apical area by the majority of the workers (Benchimol and Dimond, 1963; Coulshed and Epstein, 1963; Tafur, Cohen, and Levine, 1964; Tavel et al., 1965).

Berry (1966) advocated the use of the name cardiogram for records of præcordial movements. There is little justification for using the word apex cardiogram for tracings that may be recorded as far from the apex as the parasternal or the pulmonary areas. The site of the tracing can be indicated by prefixing the name of the area (apical, parasternal, pulmonary) or more precisely, when necessary, by a figure in which the numerator is the number of the intercostal space, and the denominator is the distance in centimetres from the midsternal line, with " $R$ " and " $L$ " abbreviations indicating whether it is on right or left of the mid-line. Thus $L, 2 / 3$ will signify left second space, $3 \mathrm{~cm}$. from mid-line. These abbreviations have been used in the present study.

According to Luisada and Magri (1959) the waves in the pulmonary area are small. There is a rela-

Received April 26, 1966. tively high presystolic wave due to contraction of the left atrium and a well-marked positive wave during early systole due to pulmonary artery pulsation. One of the tracings published by Berry (1966) shows the type of record that can be seen in cases of severe pulmonary hypertension secondary to mitral valvular rheumatic disease, and a study illustrating its value in the diagnosis of various cardiac diseases will, it is hoped, be published later.

In this paper, the præcordial movements in the pulmonary area in 27 healthy subjects as recorded by the method described by one of the authors (Berry, 1966) have been analysed and illustrated.

\section{MATERIAL AND MethodS}

There were 21 male and 6 female subjects whose ages ranged from 10 to 56 years. None showed any clinical or electrocardiographic signs of heart disease, hypertension, or anæmia.

The recordings were made with the patient lying flat and during suspended mid-expiration, as far as possible. A simultaneous electrocardiogram and carotid pulse tracing were used as reference tracings. All the tracings were taken in the second left intercostal space, at the site of maximal pulsation in the area, usually about $3 \pm 1 \mathrm{~cm}$. from the midsternal line. Fairly good tracings were obtained in nearly all the subjects.

The method of recording used has been described recently (Berry, 1966). Briefly, in this method a beam of light is focused on the area from the centre of the tubular photoelectric pulse pick-up supplied for measuring the jugular venous pulsation with Cardiopan 573*. The change in intensity of the 5 to $10 \mathrm{~mm}$. spot of light, with the movements of the chest wall at that area, is converted by the photoelectric cell into electric potential which is recorded in one of the channels of the Cardiopan. The other two channels are used to give reference tracings, the usual ones being the electrocardiogram and carotid pulse tracing, or sometimes a phonocardiogram. The three tracings can be seen on an oscilloscope which is attached to the Cardiopan and can be adjusted.
* Made by F. Liechti Ltd., Berne, Switzerland. 


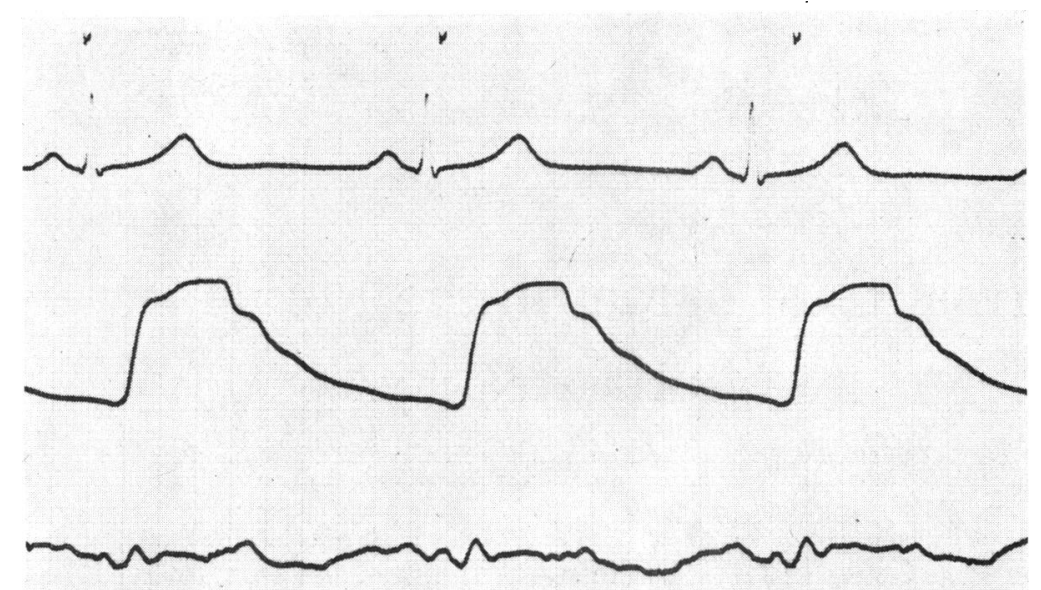

FIG. 1.-Cardiogram L, 2/4, from a man aged 37. There is an additional positive wave in mid and late systole, and a dicrotic wave. These are all discernible despite the small amplitude.

\section{OBSERVATIONS}

The amplitude of the pulsations in the pulmonary area as recorded in the tracings varied from small (Fig. 1 and 8) to large (Fig. 2 and 3) in normal healthy subjects.

Usually two positive waves and one negative wave were recorded in a tracing in each systole and diastole.
The first positive wave seen at the beginning of systole, its start coinciding with S or with the R-S interval of the electrocardiogram, is usually small, and ends before the beginning of the carotid upstroke. It is probably due to isovolumetric contraction of the ventricles, though the earliest phase of the ejection wave may contribute to it partially. Sometimes, this wave may be relatively large (Fig. 2)

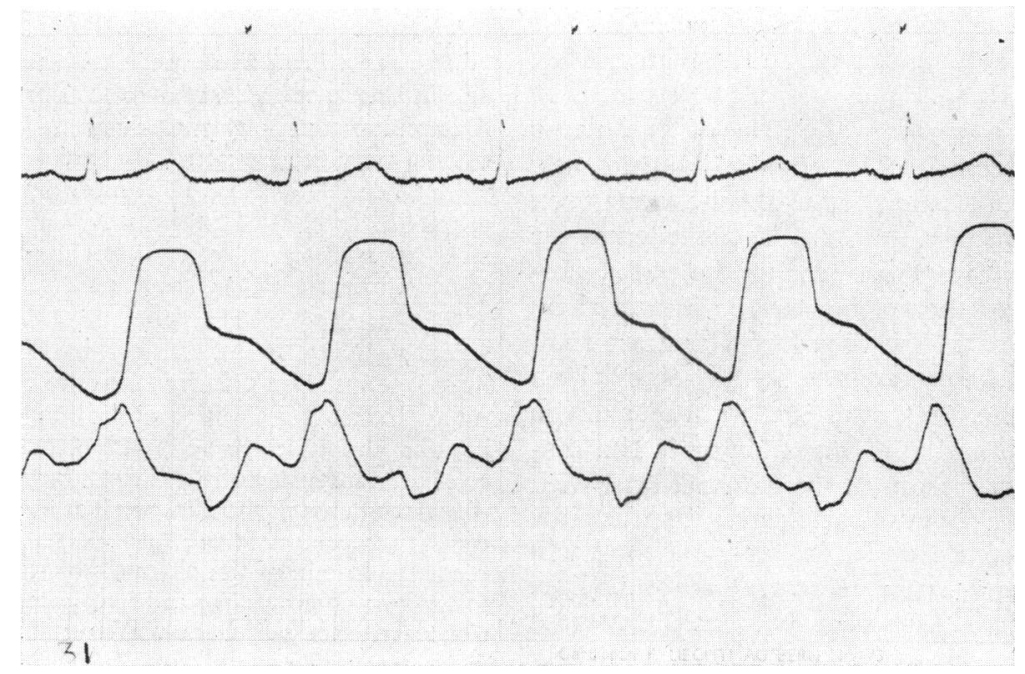

FIG. 2.-Cardiogram L, 2/3, from a girl of 14, showing a large amplitude, particularly of the positive wave in the isovolumetric contraction phase. The positive component of the early ejection phase can be distinguished. The atrial wave is just discernible; the maximum ejection wave is absent, and there is a small positive wave in the late ejection phase in most of the cycle. 


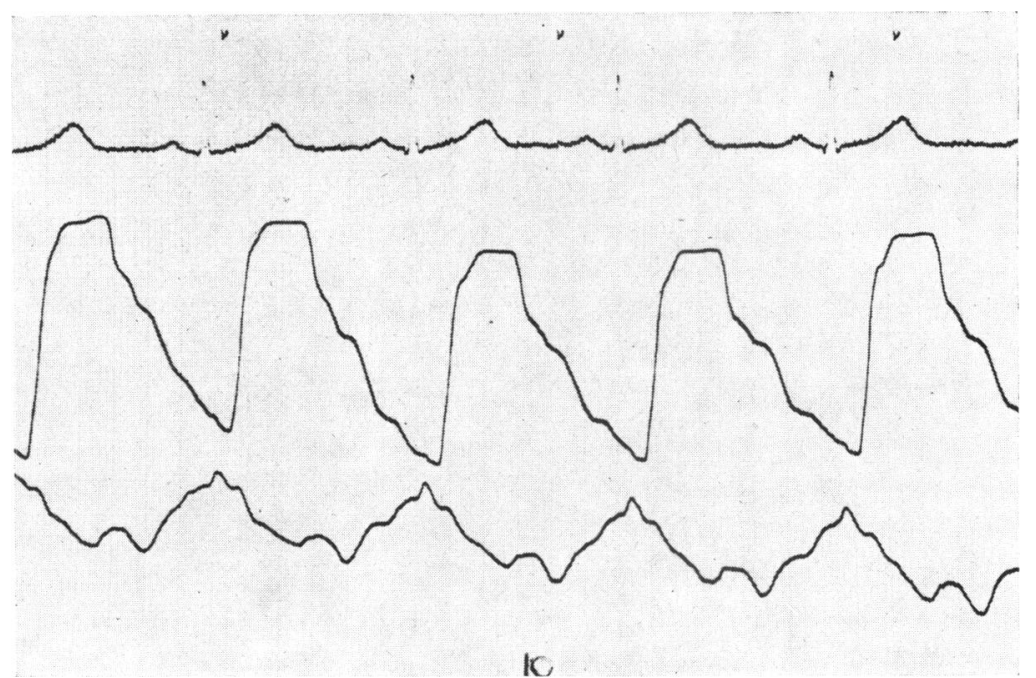

FIG. 3.-Cardiogram L, 2/2, from a girl aged 10. In addition to the two dominant waves, the negative ejection wave in systole and the positive passive filling wave in diastole, there is a well-marked dicrotic wave in all the cycles. The maximum ejection wave is very poorly marked.

and the two components may be distinguishable (Fig. 2 and 4). A positive wave in this phase could be identified in 20 out of 27 tracings. In 3, it was just discernible.

This is followed immediately by a negative wave starting at the beginning of the carotid upstroke or just before. This is the most consistent systolic wave and was present in all the subjects. In 6 , there was a positive wave in the initial phase of ejection and the negative systolic wave was delayed (Fig. 2, 4, and 5). This downstroke may continue up to the end of systole (Fig. 2), but usually it is interrupted by another positive wave, which is the maximum ejection wave and is the largest systolic positive wave (Fig. 1, 6, and 7). A midsystolic maximum ejection wave was recorded in the pulmonary area in 24 out of 27 subjects; in 2 , it was very small.

The end of the systole is recorded commonly on

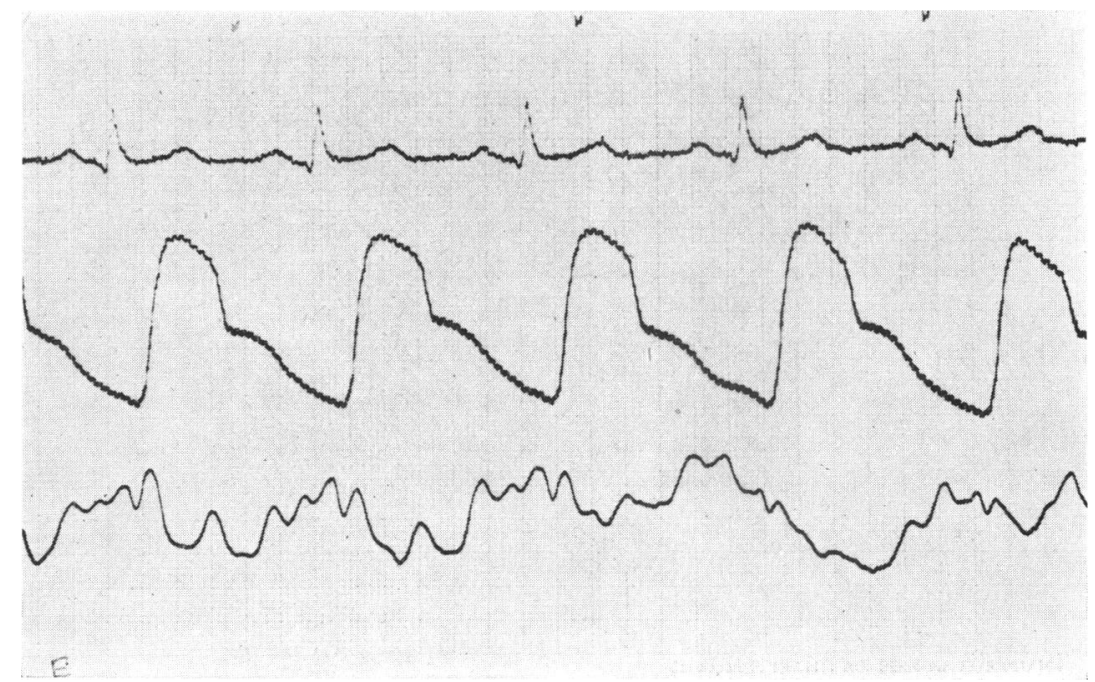

FIG. 4.-Cardiogram L, 2/3, from a girl of 16. The isovolumetric and the early ejection waves can be distinguished separately, as well as the mid and the late systolic positive waves, and the well-marked atrial and rapid passive filling waves. 


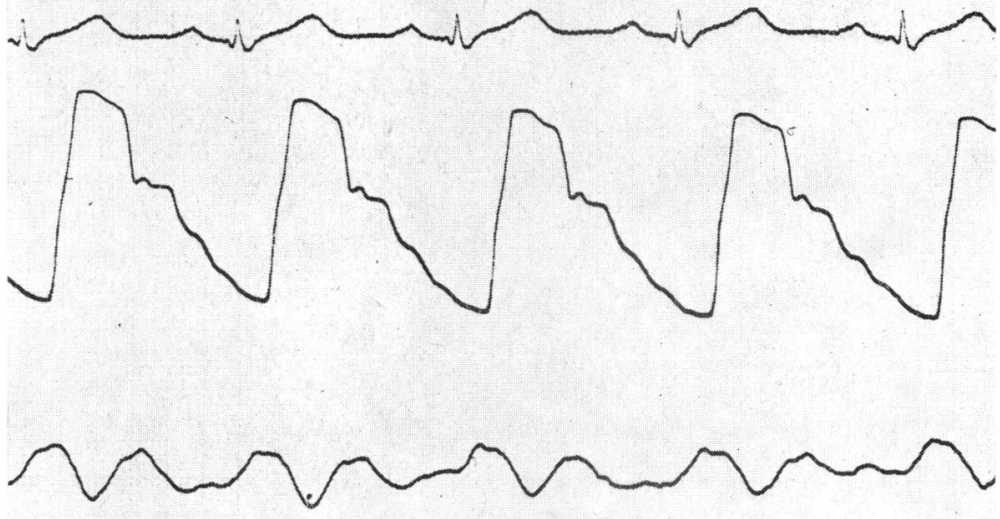

FIG. 5.-Cardiogram L, 2/3, from a man of 26. The negative systolic wave starts only in a mid-systole. The positive ejection wave is delayed to the late systolic phase. The negative wave in the early part of the isometric relaxation phase has been overlapped by a dicrotic wave.

the downward slope of the positive wave (Fig. 6 and 7), but in about half the cases there was an additional positive wave in the late ejection phase (Fig. 4 and 5).

The two positive waves in diastole are those due to passive filling and atrial contraction, respectively.

The diastolic negative wave is seen in the isometric relaxation phase and starts at the end of systole. But in about half the cases (13 out of 27), its downward slope was replaced partly or com- pletely, as in 6 subjects, by a positive wave (Fig. 1, 3 , and 5) which probably corresponds to the dicrotic wave in the underlying vessels.

The passive filling wave, consistently seen in all the subjects, starts at the end of the isometric relaxation phase or the dicrotic wave and continues till it is capped by the atrial wave due to atrial contraction. This wave starts opposite the peak of the $\mathbf{P}$ wave in the electrocardiogram and is usually rela-

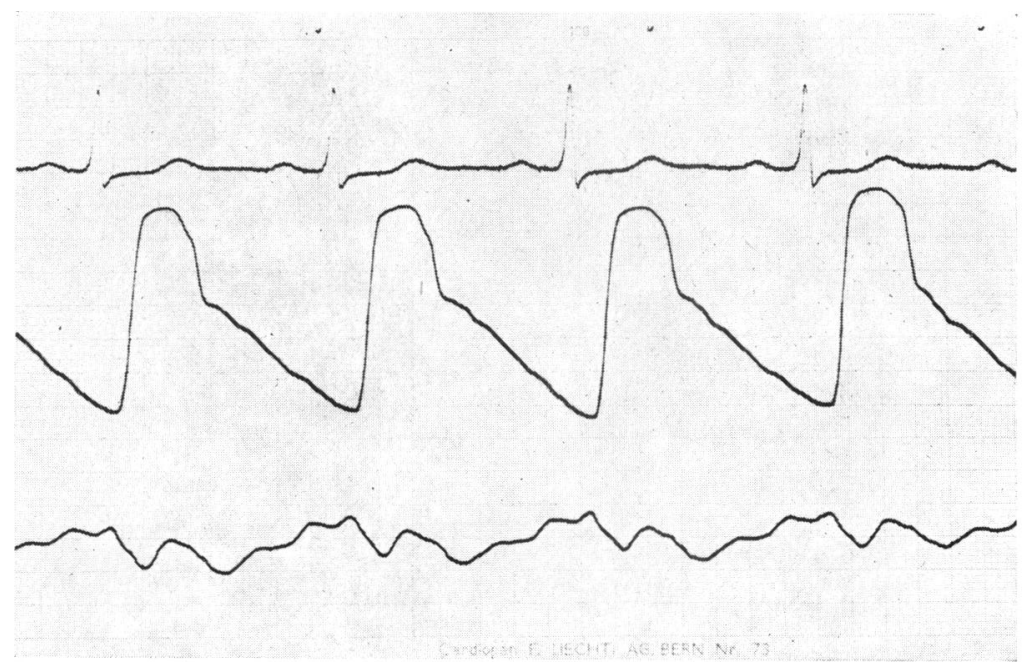

FIG. 6.-Pulmonary cardiogram of a man of 22, showing all six components of a normal tracing. 


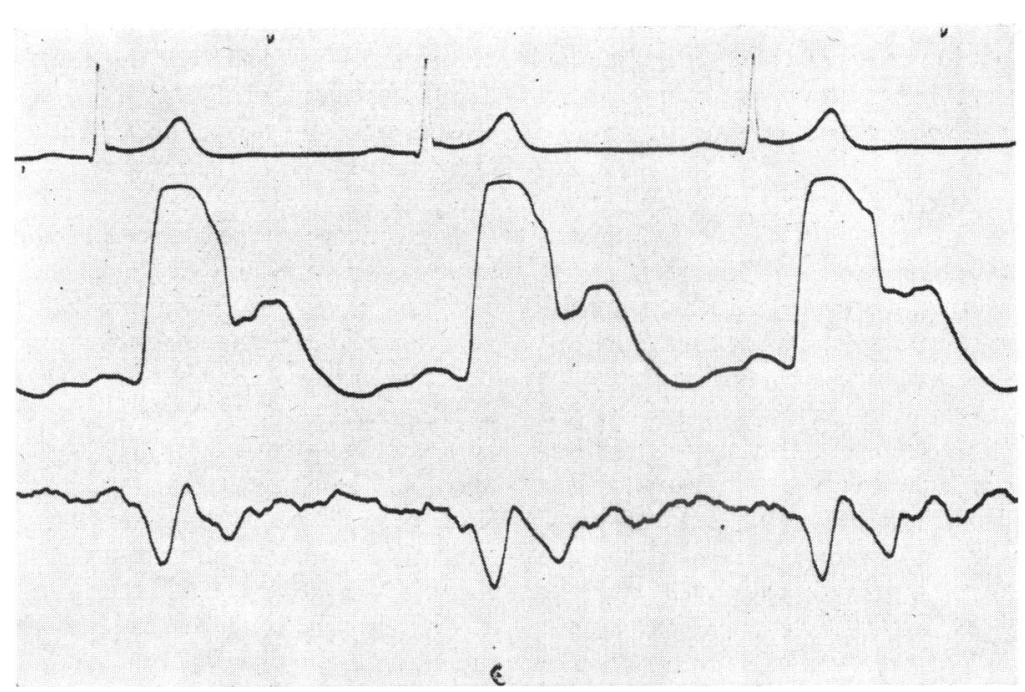

FIG. 7.-Cardiogram L, 2/3.5, of a man of 23, showing well-marked mid-systolic maximum ejection wave. In addition to the passive filling and atrial waves in diastole, there is another positive wave, the dicrotic wave, and also a less clearly defined mid-diastolic wave.

tively small. In 20 subjects it was fairly well marked, and in 3, it was just discernible, and only in 4 subjects was it not recorded.

An additional positive wave was recorded in middiastole in 8 subjects: this corresponds to the phase when maximum filling of the ventricles occurs.

\section{Discussion}

The main advantage of this method of recording præcordial movements is that there is no chest-piece which could damp or distort the movements, which is particularly likely if they are small in amplitude and force, as in the pulmonary area. It is, in effect, palpation with light. In contrast, the pressure required to keep the knob of their impulse cardiogram recorder in place was estimated by Beilin and Mounsey (1962) to lie between 100 and $200 \mathrm{~g}$. Further, thrills, if any, can be recorded simultaneously with the movements, which is a great advantage in their evaluation in diagnosis. Thrills

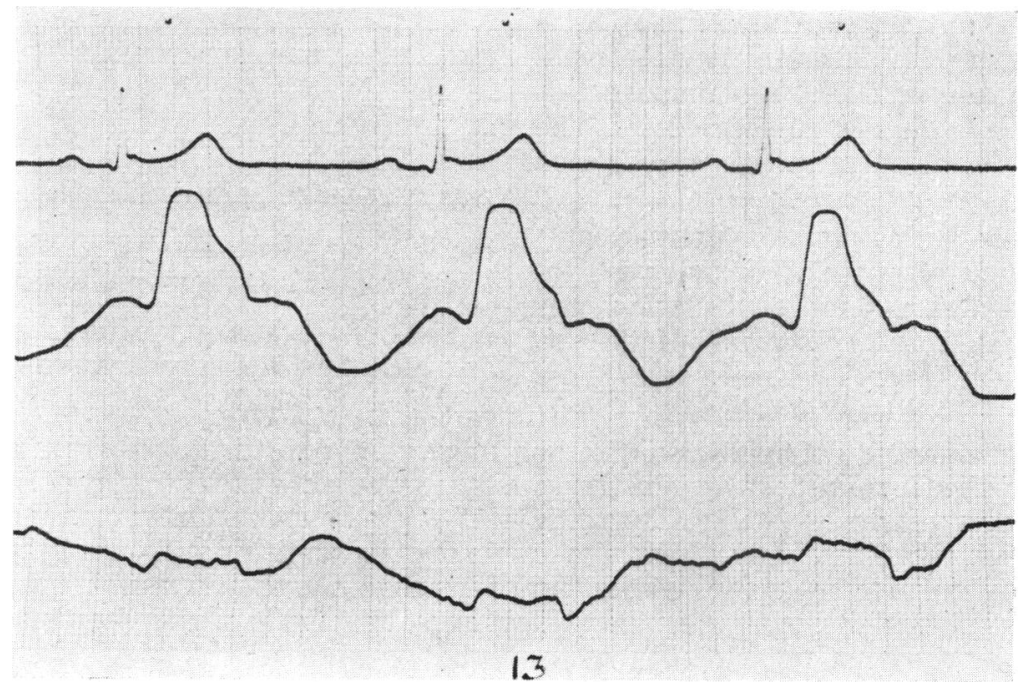

Fig. 8. - Cardiogram L, 2/3.5, of a man of 26. It is of small amplitude. The atrial and isovolumetric contraction waves have not been recorded. 
have been particularly difficult to record hitherto. The method has obvious uses in training a clinician to extract maximum information from inspection and palpation of the movements of various regions of the præcordium.

Unlike the apical and the lower parasternal areas, there is marked variability of the præcordial movements in the pulmonary area. This is not unexpected, since unlike the other two areas, the normal cardiogram in the pulmonary area is the result of changes of movement, volume, and pressure, at the minimum, in the pulmonary artery and its left branch, the left atrium and probably the infundibulum of the right ventricle during the various phases of the cardiac cycle. In disease, other chambers and vessels may assume importance. In addition, the præcordial movements, normally much less obvious here than at the apex, are affected to a large extent by the thickness of the chest wall and the position of the heart and the great vessels in the thoracic cage, and their change with age and with different builds. In the present series, the largest amplitudes were seen in younger people. The examples of pulmonary cardiograms shown here have been chosen to demonstrate the great variety of tracings obtained. Nevertheless, a basic pattern can be made out in spite of the apparent variability.

The normal pattern during systole consists of a dominant negative wave with two positive waves, one in the isovolumetric contraction phase and another in the mid-systolic maximum ejection phase, with the addition of a late systolic positive wave in half the cases. In diastole, a positive wave due to ventricular passive filling dominates the pattern and is preceded by a negative isometric relaxation wave. A dicrotic wave, conducted from the great vessels, is seen in half the subjects, and in a few the rapid passive filling of the ventricles superimposes another positive wave in the mid-diastolic phase. The end of diastole is marked by a positive wave caused by atrial contraction.

The recognition of this normal pattern and its apparent wide range of variability is important for understanding the alterations in the pulmonary cardiogram brought about by cardiovascular disease.

\section{SUMMARY}

The normal pulmonary cardiograms recorded by the method previously described by one of us (J.N.B.) have been studied in 27 normal healthy subjects.

The method has the twin advantages of freedom from damping, because of a non-applicator type of pick-up device, and simultaneous recording of any thrills present.

It is possible to get good tracings of præcordial movements in the pulmonary area in nearly all the subjects.

A pulmonary tracing usually shows two positive waves corresponding to the isovolumetric contraction phase and the maximum ejection phase, and a negative wave in the early ejection phase in systole and two positive waves, due to passive filling and atrial contraction, respectively, and a negative wave corresponding to the isometric relaxation phase in diastole. In addition, in about half the normal subjetcs there is a positive dicrotic wave in early diastole, and in about the same number another positive wave in the late ejection phase.

The amplitude of the movements as recorded in the tracing may vary from small to fairly large in health.

\section{REFERENCES}

Agress, C. M., and Nakakura, S. (1964). Variations of the vibrocardiogram over the precordium. Aerospace Med., 35, 752.

Beilin, L., and Mounsey, P. (1962). The left ventricular impulse in hypertensive heart disease. Brit. Heart f., 24, 409.

Benchimol, A., and Dimond, E. G. (1963). The normal and abnormal apexcardiogram. Amer. F. Cardiol., 12, 368.

- Wu, T. L., and Dimond, E. G. (1966). Apex cardiogram in the diagnosis of congenital heart disease. Amer. f. Cardiol., 17, 63.

Berry, J. N. (1966). A new method for recording cardiac, hepatic, and other pulsations, movements, and thrills. Amer. Heart F., 71, 17.

Coulshed, N., and Epstein, E. J. (1963). The apex cardiogram: its normal features explained by those found in heart disease. Brit. Heart f., 25, 697.

Craige, E., and Schmidt, R. E. (1965). Precordial movements over the right ventricle in normal children. Circulation, 32, 232.

Eddleman, E. E., Jr., Willis, K., Christianson, L., Pierce, J. R., and Walker, R. P. (1953). The kinetocardiogram. II. The normal configuration and amplitude. Circulation, 8, 370.

Gillam, P. M. S., Deliyannis, A. A., and Mounsey, J. P. D. (1964). The left parasternal impulse. Brit. Heart f., 26, 726.

Luisada, A. A., and Magri, G. (1959). Low frequency tracings of precordium and epigastrium. In Cardiology, ed. A. A. Luisada, Vol. 2, Part 3, p. 65. McGraw-Hill Book Company, New York.

Tafur, E., Cohen, L. S., and Levine, H. D. (1964). The normal apex cardiogram. Circulation, $30,381$.

Tavel, M. E., Campbell, R. W., Feigenbaum, H., and Steinmetz, E. F. (1965). The apex cardiogram and its relationship to hæmodynamic events within the left heart. Brit. Heart f., 27, 829. 